\title{
Translation Philosophy
}

\author{
Cem Akdogan \\ $\mathrm{PhD}$ Candidate \\ A. Nursen Durdagi \\ Assist. Professor \\ Department of Translation Studies \\ Institute of Social Sciences \\ Sakarya University, Esentepe Kampüsü, 54050, Serdivan/Sakarya
}

\begin{abstract}
Philosophy is a skeptical research struggle on comprehension of human, nature, truth, reality; in a word, of life. Philosophers assign synthetic meanings to thoughts and bring new aspects in familiar concepts with radical questions. Aspects of synthetic propositions referred here- in contradistinction to analytical ones - are always innovative. In fact, predicates gain meaning after interaction with the subject in synthetic propositions and without being identified in terms of the subject, as well as logically losing its harmony. Evaluation of scientific concepts in synthetic approach plays an important role with regard to concept-meaning-naming in translation studies. In this article, "Translation Product"' (Translatum) will be put under the scope synthetically pursuant to inter-linguistic comparison and discussed with its immanent and transcendent dimensions after re-brainstorming in translation studies. In conclusion, connections between translation philosophy and translation studies will be uncovered through projection methods and 'Translatability' will be questioned according to deconstruction as well as hermeneutic approaches.
\end{abstract}

Keywords: Translatum, Textem, Synthetic Philosophy, Translation Philosophy, Translation Studies

\section{Introduction}

Translation, for the first time, shows itself on the history stage with inter-civilizational cultural interaction after human's struggle to explain the meaning of nature. After re-writing of holy texts in target culture as of Middle Ages, it has been located in the center of discussions and begins to play an important role thereafter. When translation is put in a historical frame, it will be obvious that there are some milestones, cumulative methodvariations, and researches have categorized under certain titles as follows:

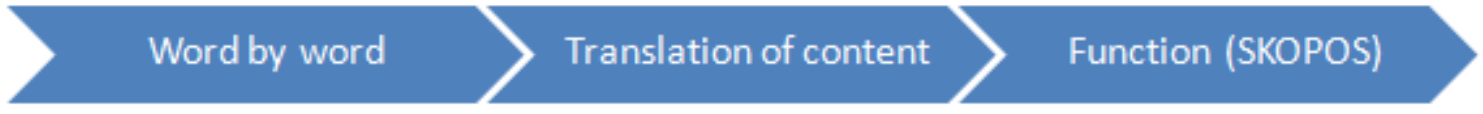

"Translation" act can be described as the struggle of making a communication apparatus acquired in familiar environments meaningful with its functional depth in an unfamiliar culture. It has essentially been approached by translation scholars to find out multidimensional answers to the question, 'is translation intrinsically possible?', from the perspectives of different disciplines.

Due to the fact that multidimensional queries require multidimensional studies philosophical and sociological evidence of translation product and translation process are traced in theoretical groundings under sub-branches of translation studies ${ }^{1}$.

Translation can be discussed from various points of view. One of them is Translation Studies, another one Translation Philosophy. It is actually difficult not only to make sharp contrasts between translation studies and translation philosophy, but also attempting to bring out similarities available between translation studies and translation criticism or sociology. Both will be a problematic evaluation, indeed (Weissbrod, 2009:59) ${ }^{2}$.

\footnotetext{
${ }^{1}$ Translation Criticism, Translation Sociology

${ }^{2}$ Quine und das Problem einer philosophischen Übersetzungstheorie
} 


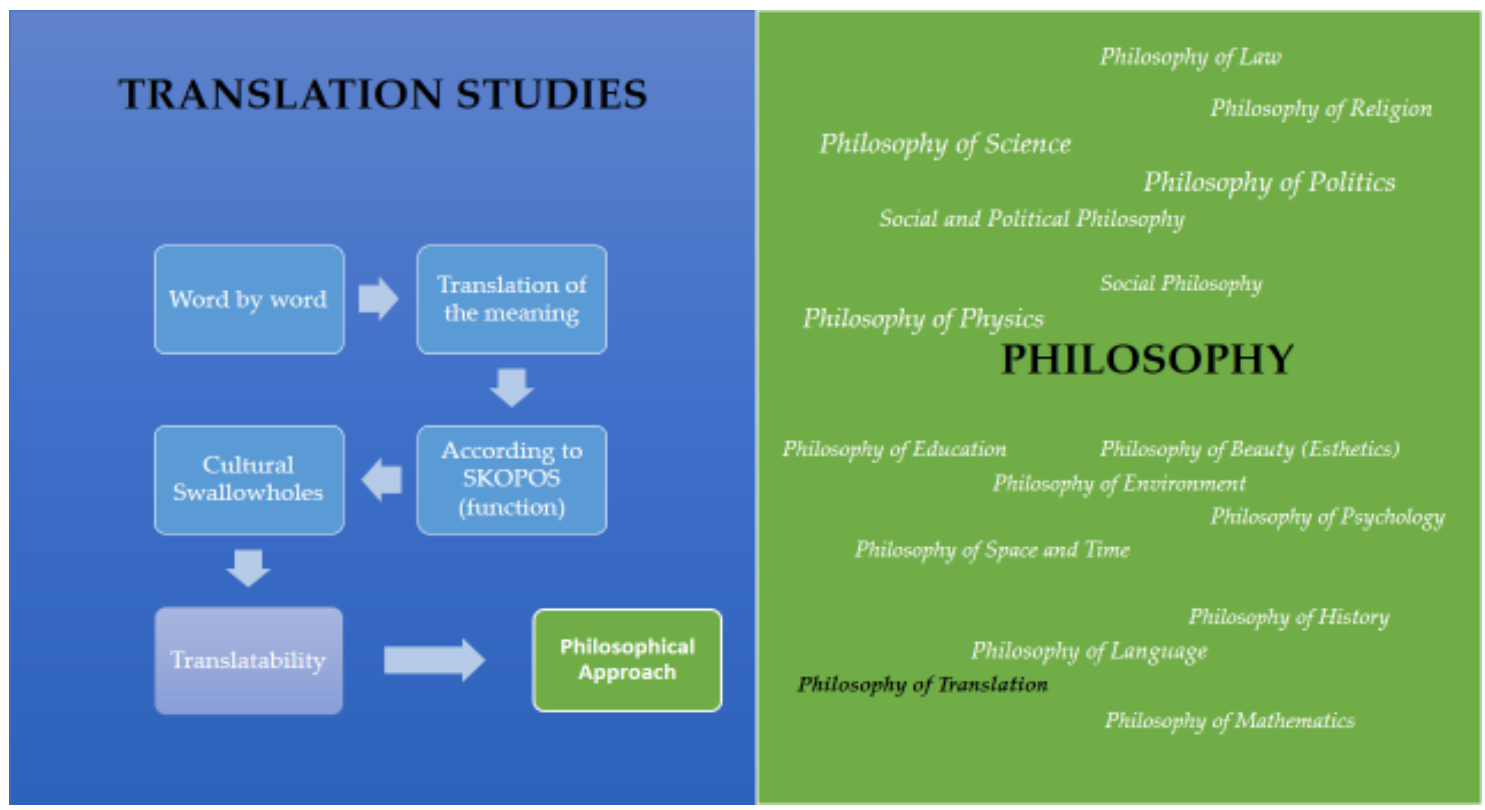

Why must translation be evaluated philosophically? What are the contributing factors bringing the translation researchers to this line of thought? Quine, in his study ${ }^{3}$, evaluates these questions with new answers (Alber, 1979: 40).

1) Is translation possible?

2) What is the hermeneutic border of the translation?

3) How can systematic amphiboly of translation be acquired?

4) What is the scope of method variation?

5) Is it possible to constitute a theory to be able to analyse systematic amphiboly in translation

6) If yes, how can philosophical infrastructure of such kind of a translation theory be established?

Determinations point that translation studies and philosophy are fundamentally in search of the same fact, known as "meaning"' and 'meaningfulness". Grünberg explains the so-called matter as the meaning existing, i.e. uncovering itself in the language, and indicates that the main problem initially required to be considered within the scope of philosophy is in relation to language (language problems), because of the fact that philosophy, first and foremost, is possible with language and can functionally be operated as much as it can represent itself in the text (Heimsoethe, 1986: 25-27). The question here is which one needs to be applied in order to approach above mentioned fact: Language or Translation Philosophy? Translation is, in any case, the representation of the various interpretable meanings textualized with subjective judgments. Hence, it would be a restricting approach to evaluate it only as a problem of language philosophy. After all, translation is both an interlingual and intralingual action as well as struggle of the subject to make the object meaningfulness.

Translation is a process of understanding the language with its cultural as well as intercultural aspects, interpretation of human itself, and the world from philosophical points of view; therefore, theoretical descriptions made in the field of translation research are always based on various premises (Chesterman, 1997:44, 45). However, being filled of "Cultural Swallow-Holes", that are visible after textualization of translation product (Translatum) depends on correct determination of the premises and is possible with a detailed translation philosophical theory determined. This fact forces translation researchers to think synthetically.

In this article, the relation of meaningfulness in translation studies has been discussed according to "das Ding an sich" (The thing itself) with respect to Kant's noumenon and phenomenon, and methods applied in synthetic philosophy. 'Translatability" has been questioned pursuant to translation philosophy. In conclusion, dynamic meaning and meaningfulness being thought by philosopher and translator have been examined with its immanent

\footnotetext{
${ }^{3}$ Unless specifically stated otherwise, translations from German and Turkish to English belong to the writer.

${ }^{4}$ Cultural Swallow-Holes is a geographical term. They come to light with low water. 
and transcendent dimensions under deconstructivism and hermeneutics. Synthetic Function of Philosophy and its Reflections in Translation Studies

\section{Synthetic Philosophy}

"Waves are washing the lone beach": Textual reflection of this sentence is a linguistic message in a communication situation coded with systematic body of rules of a language. In spite of not virtually being witnesses of this action, we create or dream the moment thanks to our previous experiences and know that when waves wash the beach, it makes a typical sound and foams, i.e. we deterministically make the water foam within the sentence. Based on this example, we can reach a general judgment and say waves washing the beach create sound and foam, and this is 'an analytical proposition'. Logic shows itself here and these propositions are always accepted as a fact. But, what is the meaning of washing the beach according to the waves themselves instead of a subject? According to Kant, the thing itself (noumenon) means 'the indefinable and unknown" (the real idea) beyond phenomenon (1).

Each sense data transmitted to our mentation center in brain via neural system transforms to knowledge and reflects to words as propositions thanks to language. Kant is of the opinion that all propositions realized as a result of mentation process are deemed synthetic; however, pure reason frequently makes an implementation attempt on noumena, sole intuition forms which can only be implemented to phenomena even though these momentaneous empty knowledge forms normally are implementable herein (Kant, 1983:59-61) ${ }^{5}$.

\section{PURE REASON}

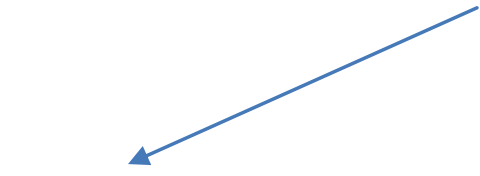

PRACTICAL

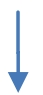

(Supernatural) NOUMENON

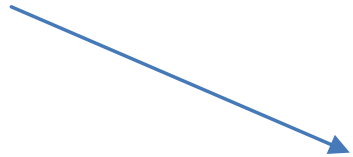

THEORETICAL

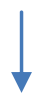

(Natural) PHENOMENON

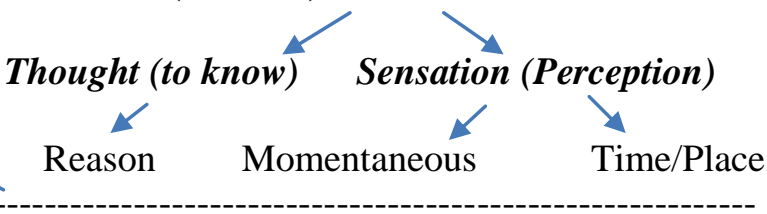

"A priori knowledge forms",

According to Kant, it is true that no certain concept about what the thing itself really is can be established beyond any possible experiments, yet it is also beyond our capability to refrain from conducting experiments or researches on such topics (Locke, 1996: 104-105). The true essence beneath the image of the object in relation to the subject refers to the existential gist.

Kant develops analytic and synthetic separation upon his thought. He determines analytic a priori - a posteriori different from synthetic a priori - a posteriori and lays special emphasis on synthetic a priori. It is because synthetic a priori-judgments ${ }^{6}$ are able to enlarge our knowledge and be true without being proven with sensory experience. For this reason, the question occupying researchers' minds appears as: What kind of a role does translation play between philosophy and cultural science? Based on Jacobson's description for intersemiotic transmutation ${ }^{7}$ in translation, it is obvious that a critical orientation to "mutual untranslatability", 8 (kritische

\footnotetext{
${ }^{5}$ Translation belongs to Ionna Kucuradi and Yusuf Ornek

${ }^{6}$ According to Kant, judgments have an explanatory characteristic in a concept we have, yet synthetic judgments enlarge our knowledge.

${ }^{7}$ Intersemiotic translation provides an interactive, participative platform with the potential to engage individuals and communities in connecting with cultures different from their own.
} 
Reflektion) is required to be developed for both disciplines. Regarding the matter, Buden points that philosophy enables critical "self-reflection" (Selbsreflektion) in cultural science and remarks that cultural forms might be reflected. What kind of a critical method can be applied? What is the frame of this method? Translation here plays a key role for the comprehension of critical thinking, and gives us the answer (Jacobson, 1896: 90-92).

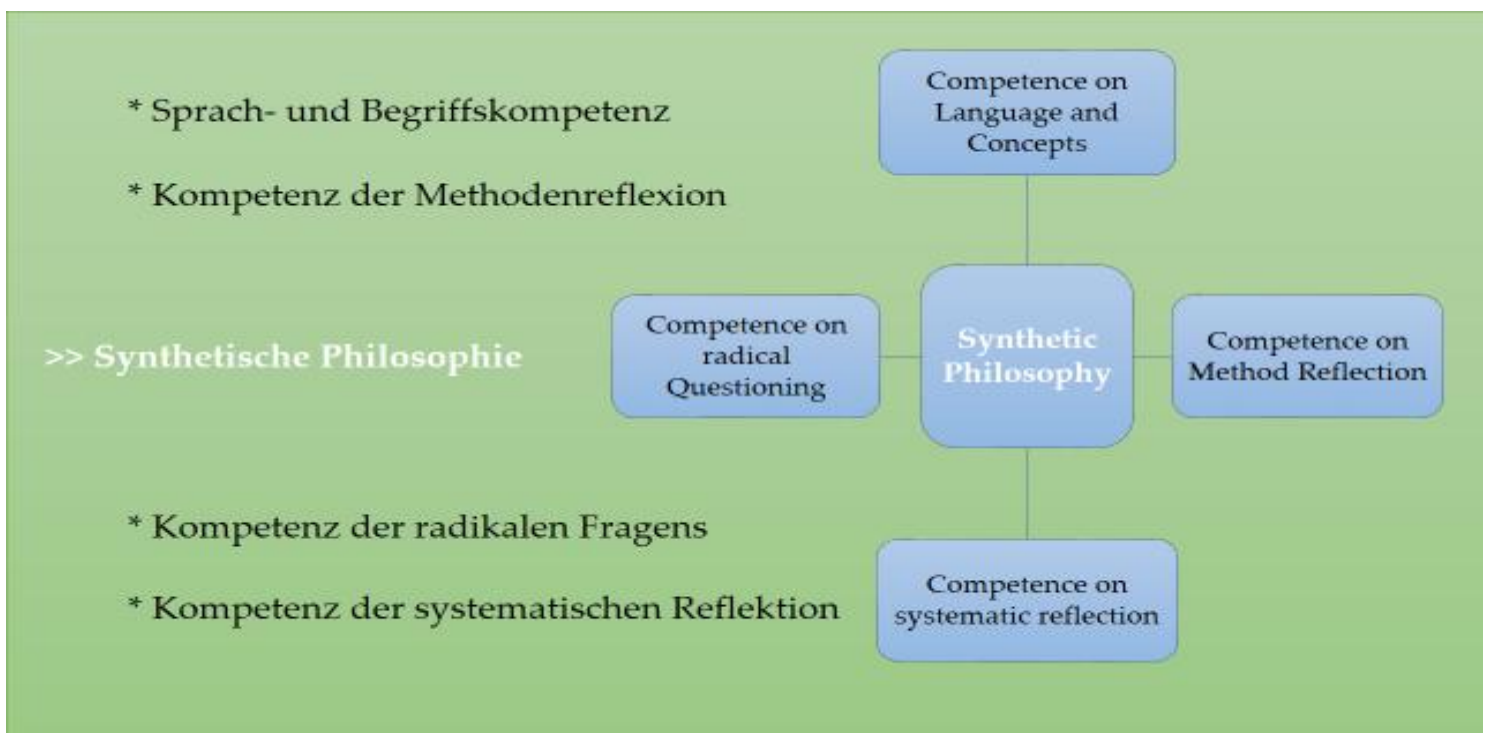

\section{Conclusion}

How cultural swallow-holes in translation are filled depends directly on a possible synthetic translation method. Concepts even having various meanings in disciplinal bodies belonging to same way of thinking show how interlingual transfer might be complicated.

Textualization of the translatum (textem) -different from sole sense-making purpose of normal source text readers - formed in translators' minds after experiential and institutional filtration (background knowledge)for the purpose of making the "Skopos" understandable to target audience shapes according to systematic spontaneous decisions, and draws the line of "translatability" or 'untranslatability'.

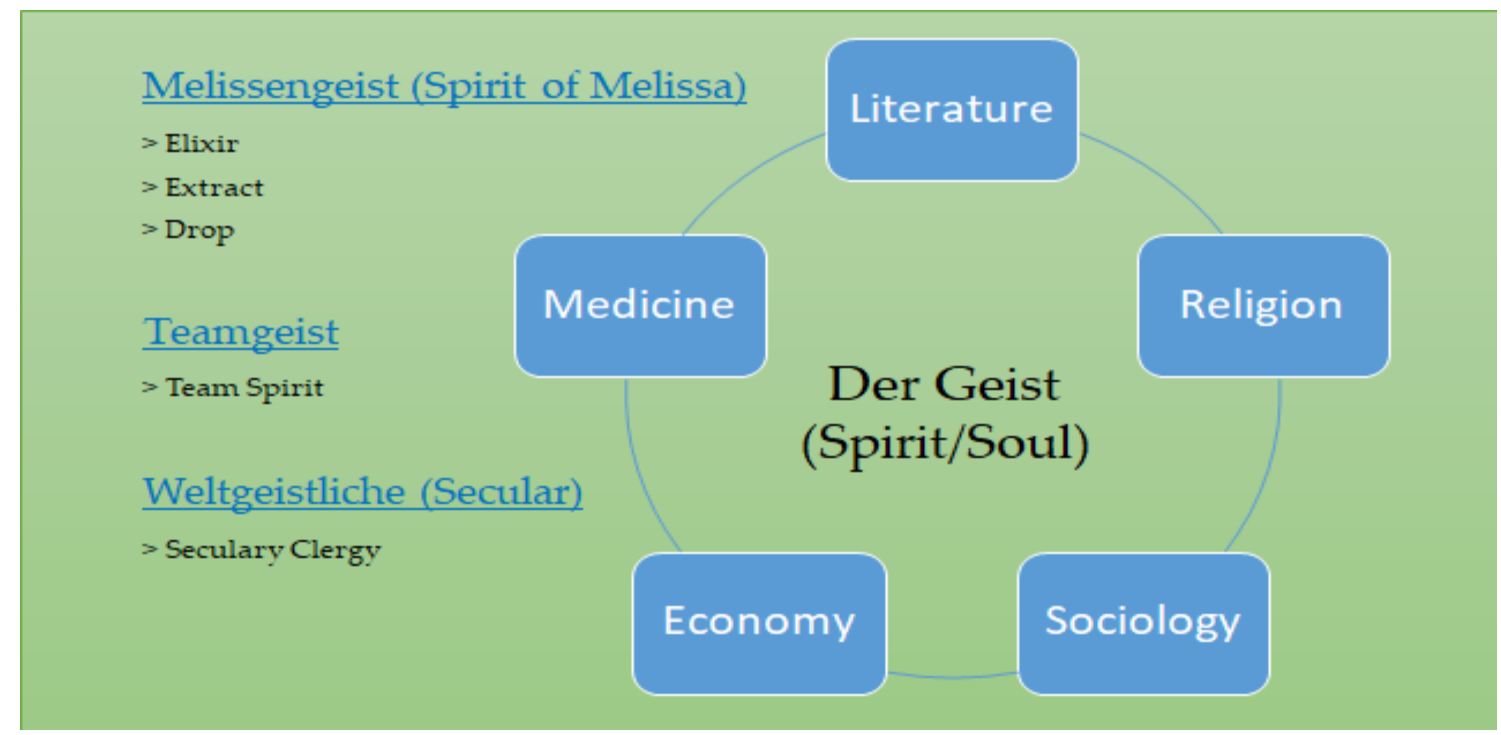

\footnotetext{
${ }^{8}$ Interdisciplinary transmutation of philosophy in cultural studies; interdisciplinary transmutation of cultural studies in philosophy 
As a material of translation, Weissenhofer defines concepts as abstract cognitive data independent of the language required for effective communication (1994: 322). This is even more predominant in terminological concepts which establish the function of academic studies and their relation to other disciplines, thus requiring the most plain and clear connection between the concept's reflection in language and its meaning. The given examples clarify the interpretability of the terminological use in Turkish and German - thought - reflection and given meaning. Weissenhofer evaluates each concept as a translation material and describes them as an abstract and cognitive data required for communication (Weissenhofer, 1994: 322).
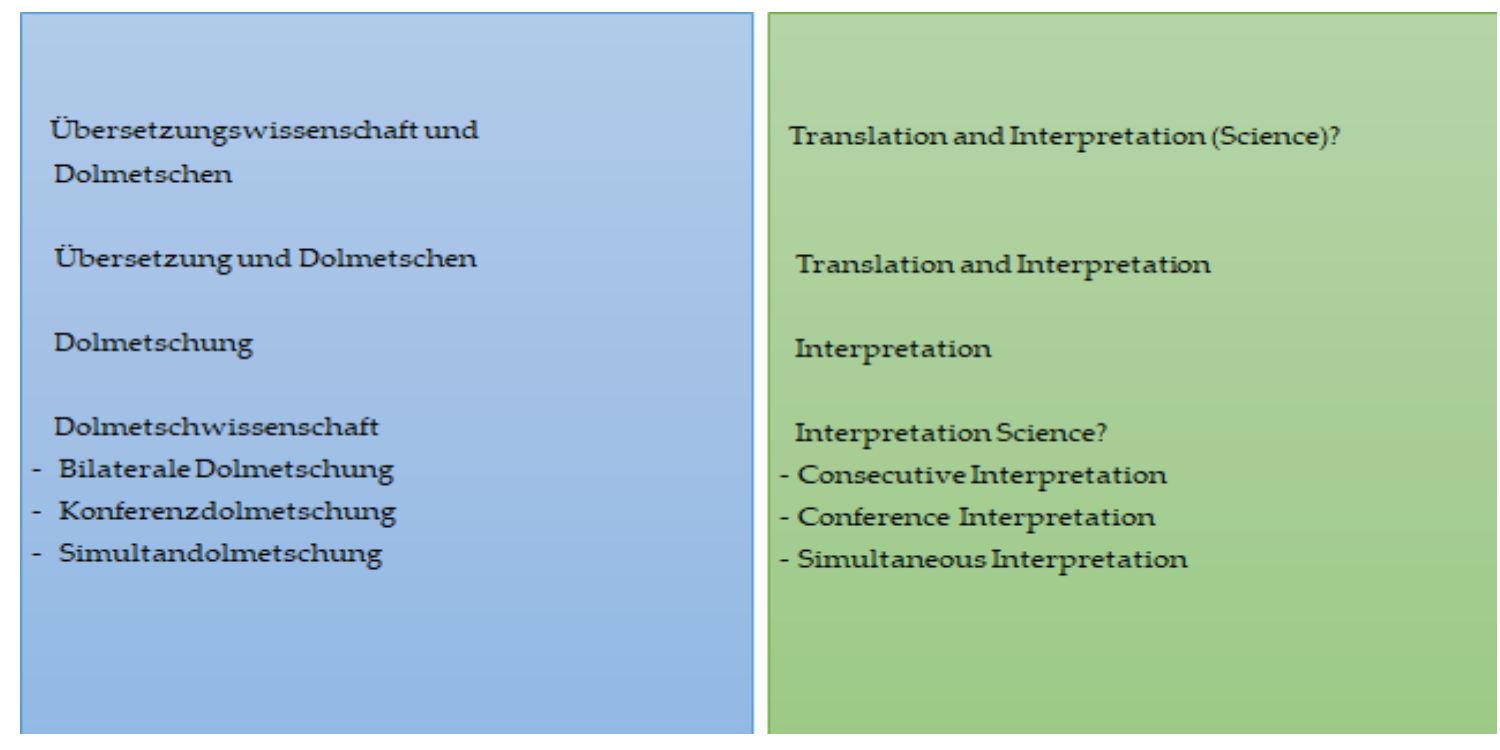

Quine's work focused on Kant's philosophy and evaluations for the purpose of establishing a general philosophy of translation examine the relationship of "analytic" and "synthetic" qualified informative concept with the actual (what is actually meant) (Beckermann and Perler, 2003:4,5).

In conclusion, approaching concepts of translation studies as well as other disciplines with a synthetic perspective requires a certain mental (logical) competence. Does the issue of incomprehensibleness in translation (Ricoeur's proposal of dynamic meaning) exist or is there a definitive untranslatability, drawing on J. Derrida's suggestion that the meaning progresses infinitely and is not static (Weissbrod, 2009:60). Whatever the answer may be, it has become inevitable to examine this approach with the perspective of translation philosophy.

\section{References}

ALBER, Karl (1979), Quine und das Problem einer philosophischen Übersetzungstheorie, Verlag/München

CHESTERMAN, Andrew (1997), Memes of translation: The spread of ideas in translation theory. Amsterdam and Philadelpia

HEIMSETHE, H. (1986), Immanuel Kant'1n Felsefesi, (Translation to Turkish by Takiyettin Mengüşoğlu), Remzi Kitapevi, Istanbul

JACOBSON, Roman (1980), The Frame work of Language, MHS, Michigan

KANT, Immanuel (1983) Prolegomena, Ankara

LOCKE, J. (1996), İnsan anlığg üzerine bir deneme (Translation to Turkish by Vehbi Hacikadiroğlu), Kabalc1 Yayınevi, İstanbul

PERLER, Dominic - BECKERMANN, Ansgar (2004), Klassiker der Philosopie heute, Reclam, Stuttgart

WEISSBROD, Rachel (2009), Philosophy of Translation meets Translation Studies, John Benjamin Publishing Company, Israel

WEISSENHOFER, Peter (2003), Zur Rolle der terminologischen Begriffslehre in der Translationswissenschaft, Translation Studies: An Interdiscipline, Selected Papers from the Translation Studies Congress, Vienna 